\title{
Agricultura Familiar e Desenvolvimento Paranaense entre 1996 e 20061
}

Familiar farm and Paraná State's development from 1996 to 2006

\author{
Christian Luiz da Silva ${ }^{2}$ \\ Caio Cezar Zerbato 3 \\ Weimar Freire Da Rocha J ${ }^{4}$
}

\begin{abstract}
Resumo: A agricultura familiar é relevante para o processo de modernização tecnológica do agronegócio brasileiro e, principalmente, tem fortes laços regionais. Dessa forma, a agricultura familiar é amortecedora das crises no setor agrícola e agente de desenvolvimento local, mas questionase, com este trabalho, se a agricultura familiar constitui-se moderna e competitiva, potencializando o desenvolvimento local sustentável e a melhoria da qualidade de vida no campo. O objetivo geral deste trabalho foi avaliar se as regiões geográficas paranaenses com um modelo agrícola predominante pautado na agricultura familiar possuem melhores indicadores sociais e econômicos. Trata-se de um método de pesquisa aplicado, com estatística descritiva e de correlação entre indicadores socioeconômicos e dos dados do censo Agropecuário de 1995/ 1996 e 2006. Como resultado observouse que onde a agricultura familiar é predominante verifica-se melhores indicadores econômicos e sociais. Ainda, o estudo demonstrou como esse modo de produção caracteriza-se por ser o maior gerador de empregos no meio rural e promover a sustentabilidade ambiental na agricultura.
\end{abstract}

Palavras-chave: agricultura familiar; Paraná; desenvolvimento; indicadores socioeconômicos.

\begin{abstract}
The family farm is relevant to the technological modernization of Brazilian agribusiness, and especially has strong regional ties. Thus, family farming is damping of crises in agriculture and local development agent, but wonders, with this work, where family farming constitutes a modern and competitive, increasing local sustainable development and improving the quality of life in the field. The objective of this study was to assess whether the geographical regions of Paraná with a predominantly agricultural model family ruled in agriculture have better social and economic indicators. This is a research method applied, with descriptive statistics and a correlation between socioeconomic indicators and the Agricultural Census data from 1995/1996 to 2006. As a result it was observed that where family farming is prevalent there is better economic and social indicators. Still, the study showed how this method of production is characterized by being the largest generator of jobs in rural areas and promote environmental sustainability in agriculture.
\end{abstract}

Key Words: familiar farm; Paraná; development; social and economic indicators.

JEL: O13, Q15, R11.

\section{Introdução}

A partir de 1950, os países subdesenvolvidos idealizaram planos de industrialização intensiva, o que caracterizava a busca pelo desenvolvimento econômico. Para Melo e Parré (2007), esse contexto caracterizou o setor agrícola como o responsável por dar suporte ao processo de industrialização, pois a agricultura deveria expandir suas relações com o setor urbano-industrial. Neste

\footnotetext{
${ }^{1}$ Artigo recebido em junho de 2010 e aprovado em setembro de 2010.

2 Economista. Pós doutor em administração pela USP. Professor do programa de mestrado e doutorado em tecnologia da UTFPR. E-mail: christianlsilva@uol.com.br

3 Economista. Técnico da Caixa Econômica Federal. Pesquisador da PUCPR. E-mail: caio_cezar87@hotmail.com

${ }^{4}$ Engenheiro. Doutor em engenharia de produção pela UFSC. Bolsista produtividade do CNPq. Professor do mestrado e doutorado em Desenvolvimento Regional e Agronegócios da Unioeste/Campus Toledo. E-mail: weimar.junior@unioeste.br
} 
aspecto, o crescimento econômico seria consequência do desenvolvimento agrícola associado ao suporte do desenvolvimento industrial. Estes autores destacam que a partir do final da década de 1960 e início da década de 1970, os princípios da Revolução Verde caracterizaram um novo padrão de produção agrícola, pautado pela forte intervenção estatal por meio do financiamento agrícola subsidiado aos agricultores e uma intensa transformação de base técnica na organização da produção.

Os incentivos, entretanto, não privilegiaram uniformemente todas as regiões do país, nem todos os produtores. O grande capital agrícola foi o privilegiado dessa reestruturação de base tecnológica na agricultura brasileira, pois essas ações estimularam o êxodo rural, a concentração fundiária e a acumulação de capital.

A agricultura paranaense também se inseriu nesse processo de modernização. Segundo Melo e Parré (2007), o setor agrícola do Paraná passou por grandes transformações a partir da década de 1970, com alterações de sua estrutura produtiva, que levaram a mudanças no seu padrão de competitividade. A agricultura no Estado passou a atuar com destaque no agronegócio nacional. Para os mesmos autores, entre 1980 e meados de 1990, as crises e instabilidades econômicas impuseram limites ao desenvolvimento agrícola paranaense e brasileiro, no entanto, puderam ser percebidas mudanças na pauta de produção e a incorporação de novas tecnologias ao processo produtivo.

Com a abertura comercial em 1990 e a valorização do câmbio, as mudanças no setor agrícola tornaram-se mais rápidas, na medida em que, houve um deslocamento da produção para regiões mais propicias a sistemas mais produtivos e competitivos. Para Amorim e Staduto (2007), essa conjuntura possibilitou que diversos agricultores procurassem novas atividades estáveis e mais rentáveis, assim, um significativo contingente de agricultores familiares teve sua situação de exclusão ainda mais agravada. As consequências foram a concentração do acesso a terra, a modificação do tipo e/ ou nível de emprego e a redução da oferta de alimentos básicos, além de a agricultura familiar organizar-se de forma a ser o principal agente de processos de agroindustrialização de alimentos de pequeno porte.

Para Guilhoto et al. (2007), o Produto Interno Bruto (PIB) do agronegócio em 2005 representou 27,9\% do PIB nacional. O agronegócio familiar e suas cadeias produtivas representaram neste mesmo ano 9\% do PIB brasileiro. A região Sudeste detém 55\% do PIB nacional, no entanto, no chamado agronegócio familiar 5 sua participação corresponde a $39 \%$ do produto gerado. A região Sul destaca-se no segmento familiar com 44\% de participação do PIB do agronegócio. O PIB do Paraná, no agronegócio familiar, em 2004 representou 17,97\% do PIB total do Estado, enquanto, neste mesmo ano, a agricultura patronal participou com $26,85 \%$ do produto.

Segundo a Fundação Instituto Brasileiro de Geografia e Estatística (IBGE) no Censo Agropecuário de 1995/ 1996, a estrutura do campo paranaense contava com aproximadamente 300 mil propriedades rurais que possuíam menos de 50 (ha) aliadas a uma economia de base familiar.

\footnotetext{
5 Neste caso o termo agronegócio familiar é utilizado, pois "reflete o tratamento dado pelos pesquisadores, que considera a agricultura familiar como um segmento do complexo maior da chamada economia do agronegócio, conferindo-lhe uma identidade econômica própria e que deve ser compreendida enquanto atividades das cadeias produtivas da agricultura familiar" (GUILHOTO et al., 2007, p. 10).
} 
A agricultura familiar constitui-se como amortecedora das crises no setor agrícola e agente de desenvolvimento local (VEIGA, 2000, p. 97 apud SCHMITZ, 2003). Por isso, questiona-se, com este trabalho, se a agricultura familiar constitui-se moderna e competitiva, potencializando o desenvolvimento local sustentável e a melhoria da qualidade de vida no campo.

O objetivo geral deste trabalho é avaliar se os municípios paranaenses ${ }^{6}$ pertencentes a um modelo de desenvolvimento agrícola predominante pautado na agricultura familiar possuem melhores indicadores econômicos e sociais. A hipótese nula é de que a agricultura patronal desenvolvida por um modelo exógeno no grande latifúndio caracteriza-se como um agente de desenvolvimento local com caráter distributivo de renda e geradora de emprego, além de promover a sustentabilidade ambiental e o desenvolvimento rural. A principal hipótese alternativa do presente estudo é que a agricultura familiar, nos locais onde se encontram predominante a agricultura familiar, proporciona melhores indicadores econômicos e sociais. Pois, pressupõem-se a necessidade do reconhecimento científico, político e social para o avanço desse modo de agricultura voltada para a sustentabilidade. O artigo está organizado em 5 seções, incluindo esta introdução. A segunda seção trará o conceito e as características da agricultura familiar. A terceira seção o método de pesquisa e a quarta seção a análise dos resultados, para apresentar as considerações finais seguidas das referências.

\section{Agricultura Familiar e Desenvolvimento: uma Abordagem Teórica}

Os estudos sobre a agricultura familiar remetem-se as raízes históricas das discussões acerca do campesinato, do desenvolvimento do capitalismo e da questão agrária propriamente dita. Lênin (1985) e Kautsky (1986) são autores clássicos marxistas da questão agrária e partilham dessa corrente de pensamento sobre o papel progressista do capitalismo no campo. A teoria marxista discorre sobre a fatal extinção de uma chamada economia camponesa, por não ser uma cultura racional, atrasar o progresso científico no campo, e, além disso, pelo aumento do número dos grandes estabelecimentos agrícolas e a proletarização das massas.

Para Abramovay (1998), não é possível encontrar nas obras de Karl Marx uma teoria sobre a questão agrária, haja vista, este termo estar historicamente relacionado a situações conjunturais e ideologias políticas momentâneas. Marx, em boa parte dos seus estudos, se ateve sobre o desenvolvimento do capitalismo na agricultura, no entanto, a produção familiar não é estudada em seus escritos devido à própria estrutura lógica de sua obra. Na linha de pensamento marxista, o camponês ou a economia camponesa tem sua extinção prevista, à medida que o agricultor proprietário dos meios de produção se tornará um capitalista, ou a perda desses meios o levará gradualmente para a classe assalariada.

Em oposição às idéias marxistas do camponês como certo tipo de pequena fração social, pois não vende sua força de trabalho e nem explora a força de trabalho alheio, o autor russo Alexander Chayanov - estudioso dos assuntos ligados ao desenvolvimento agrícola, busca explicar através de seus trabalhos uma economia

\footnotetext{
6 Os municípios são também subdivididos geograficamente para uma análise regionalizada, segundo o critério de Mesorregiões do IBGE - ao todo são 10 (dez), são elas: Noroeste, Centro-Ocidental, Norte Central, Norte Pioneiro, Centro-Oriental, Oeste, Sudoeste, Centro-Sul, Sudeste e Metropolitana de Curitiba (IPARDES, 2004a).
} 
camponesa racional e positiva, oferecendo novas ideias sobre o paradoxo da reprodução da unidade de produção familiar na agricultura contemporânea.

Para Wanderley (1998), Chayanov foi quem originalmente discorre em seus estudos sobre o modo de funcionamento das unidades familiares de produção na agricultura. Segundo as idéias de Chayanov, a unidade de produção familiar possui condições de funcionamento que a diferenciam da unidade de produção capitalista. Na produção familiar inexiste a mais-valia, o trabalho empregado não é extraído nem apropriado de um trabalhador alheio, a fonte de trabalho da propriedade é aquela proveniente do proprietário dos meios de produção. Nesta relação de trabalho, o produtor familiar e sua família têm uma relação de esforço físico e mental na unidade de produção, além de que, o mesmo deve prover sua reprodução social, cabendo a ele gerir os recursos necessários para a manutenção e expansão patrimonial. Segundo Abramovay (1998), Chayanov introduz o conceito de "auto-exploração" no campesinato - é certo de que outras classes sociais podem se apropriar do trabalho do camponês, mas a exploração do trabalho é intrínseca na relação entre os esforços despendidos e a satisfação de suas necessidades. No intuito de diferenciar a unidade de produção capitalista da unidade de produção agrícola familiar Chayanov (1981) apud Wanderley (1998) discorre:

Na economia agrícola familiar, a família, equipada com meios de produção emprega sua força de trabalho no cultivo da terra, e recebe como resultado de um ano de trabalho certa quantidade de bens. Uma simples observação de estrutura interna da unidade de trabalho familiar é suficiente para compreender que é impossível, sem a categoria salários, impor a esta estrutura o lucro líquido, a renda e o juro do capital, como categorias econômicas reais, no sentido capitalista da palavra (CHAYANOV, 1981 apud WANDERLEY, 1998, p. 30-31).

Na agricultura familiar, além da ausência de mais-valia pela não apropriação ou exploração de trabalho alheio, a renda familiar é um todo indivisível, pois a "formação se origina e depende de um organismo econômico único" (ABRAMOVAY, 1998, p. 61).

O capital financeiro e a agroindústria definitivamente transformaram a divisão social do trabalho na unidade familiar. O cooperativismo para Chayanov seria uma das mais importantes modalidades da socialização que se iniciava no trabalho camponês. Desse modo, a produção familiar longe de ser fadada ao desaparecimento, se integraria ao mercado, pois o funcionamento da unidade de produção familiar integrada a agroindústria capitalista ou cooperativa, eliminaria o balanço entre o trabalho e o consumo garantindo que o desenvolvimento da agricultura familiar seja progressista, absorvendo as inovações tecnológicas e consolidando o produtor familiar como agente social do progresso.

Partilhando da visão progressista referente ao agricultor familiar de Alexander Chaynov, as cooperativas, na visão de Marschall (2005), são vistas como uma forma de sobrevivência do agricultor familiar no sistema capitalista. A inexistência de políticas públicas eficientes e específicas voltadas para a agricultura familiar ocasiona a associação dos agricultores familiares em torno de seus interesses, assim constituise em "uma forma de resistência e de articulação de forças frente às demandas externas que impõem tecnologias, produtos e padrões de consumo, mormente voltados para os interesses do capital monopolista” (MARSCHALL, 2005, p. 47).

O tema agricultura familiar para Abramovay (1997), tornou-se promissor no meio intelectual a partir da década de 1970, e repetitivo nos anos de 1980, entretanto, 
o autor destaca a partir de 1990, uma mudança de percepção sobre o assunto por meio de estudos pioneiros, que não delimitavam apenas o universo familiar pela superfície dos estabelecimentos agrícolas.

Os perceptíveis avanços nas pesquisas sobre a agricultura familiar devem-se a mudanças nos métodos e nas técnicas de estudos, ademais a frequente associação até então utilizada nas pesquisas, entre a agricultura familiar e a pequena produção fadada ao desaparecimento, tornou-se não usual. Duas linhas de pensamento passaram a ser enfatizadas nas conclusões das pesquisas no pós anos 90: o agricultor familiar passou a ser conhecido diferentemente daquele habitual pequeno produtor, ou seja, percebeu-se sua capacidade de buscar a tomada de crédito junto as instituições financeiras, seu comportamento não era basicamente de aversão ao risco, praticavam a inovação tecnológica e a constante modificação e aprimoramento do processo produtivo, além da produção não ser exclusiva para o mercado interno e muito menos apenas para subsistência. O segundo ponto de análise é a percepção da estrutura social de desenvolvimento agrícola, pois a partir de estudos comparativos em relação aos países de capitalismo central, conclui-se que estes países desenvolveram sua base social de estrutura agrícola a partir de unidades familiares de produção. (ABRAMOVAY, 1997).

De fato, as mudanças na percepção sobre a agricultura familiar no meio acadêmico e na política condicionaram que sindicalistas se articularam através da Confederação Brasileira de Trabalhadores na Agricultura (CONTAG), com o apoio de instituições internacionais, especialmente a Organização das Nações Unidas para a Agricultura e Alimentação (FAO) e o Banco Internacional de Reconstrução e Desenvolvimento (BIRD), assim a esses atores deve-se a valorização do termo agricultura familiar no Brasil (NEVES, 2006).

Na legislação brasileira, no inciso II, do artigo 4ํㅜ , do Estatuto da Terra, a propriedade familiar é definida pela Lei no 4.504 de 30 de novembro de 19647, na qual consta o seguinte texto:

\begin{abstract}
"Propriedade Familiar", o imóvel rural que, direta e pessoalmente explorado pelo agricultor e sua família, lhes absorva toda a força de trabalho, garantindo-lhes a subsistência e o progresso social e econômico, com área máxima fixada para cada região e tipo de exploração, e eventualmente trabalhado com a ajuda de terceiros.
\end{abstract}

A definição da área máxima das propriedades rurais está estabelecida na Lei no 8.629, de 25 de fevereiro de 1993, nesta lei os imóveis rurais com até 4 (quatro) módulos fiscais são considerados pequenas propriedades e, como médias propriedades os imóveis que estão entre 4 (quatro) e 15 (quinze) módulos fiscais. A política agrícola a partir dos anos de 1990 voltou-se para a construção de um agricultor familiar como sujeito de direitos e, em outubro de 1995 houve o lançamento do Programa Nacional de Fortalecimento da Agricultura Familiar (PRONAF). A oficialização do programa ocorreu através do Decreto no 1946 , de 28 de junho 1996; Resolução 2310, de 29 de agosto de 1996, com intuito de promover o desenvolvimento sustentável do segmento rural constituído pelos agricultores familiares.

Bittencourt e Bianchini (1996) buscam ampliar o conceito de agricultores familiares, pois percebem nos agricultores mais capitalizados a existência de

\footnotetext{
${ }^{7}$ Disponível para consulta no sitio eletrônico <http:/ / www.planalto.gov.br/ ccivil/leis/ L4504.htm>.
} 
contratação de algum tipo de serviço, seja ele na forma de parceria, como também trabalhadores temporários - devido à sazonalidade de diferentes culturas, ou até mesmo trabalhadores permanentes. Assim, para esses autores o conceito de agricultura familiar é definido como:

Agricultor familiar é todo aquele (a) agricultor (a) que tem na agricultura sua principal fonte de renda ( $+80 \%$ ) e que a base da força trabalho utilizada no estabelecimento seja desenvolvida por membros da família. É permitido o emprego de terceiros temporariamente, quando a atividade agrícola assim necessitar. Em caso de contratação de força de trabalho permanente externo a família, a mão-de-obra familiar deve ser igual ou superior a $75 \%$ do total utilizado no estabelecimento (BITTENCOURT E BIANCHINI, 1996, p. 1415).

Na busca pela delimitação do universo familiar, os estudos da FAO/INCRA (2000) entendem a complexidade do tema devido às dificuldades existentes em separar os agricultores familiares dos patronais. Existem diversos tipos de agricultores que operam seus interesses de formas diferentes e possuem sua própria racionalidade, as múltiplas variáveis dificultam a aplicação empírica de uma metodologia conceitual para a tipificação da agricultura familiar. Assim, a conceituação adotada classifica os produtores de acordo com o processo de produção e de que forma a exploração do estabelecimento é exercida. O universo familiar foi delimitado nas propriedades que simultaneamente atendiam as seguintes condições: "a direção dos trabalhos do estabelecimento era exercida pelo produtor; o trabalho familiar era superior ao trabalho contratado" (FAO/ INCRA, 2000, p. 9). A dimensão da propriedade familiar foi estabelecida através da delimitação de uma área máxima regional como o limite superior para o tamanho dessas propriedades.

A definição de agricultura familiar pode estar relacionada como uma forma de gestão do estabelecimento e sua organização produtiva, além da possibilidade de se pressupor uma agricultura de subsistência ou uma economia camponesa organização produtiva orientada pela vida familiar, assim visando à construção de uma definição ampla, para Neves (2006, p. 47) "a agricultura familiar corresponde a formas de organização da produção em que a família é ao mesmo tempo proprietária dos meios de produção e executora das atividades produtivas".

As definições sobre a agricultura familiar abordadas no meio acadêmico discorrem sobre os seguintes aspectos dessa forma de organização produtiva: referem-se ao tamanho do estabelecimento rural, do tipo de mão-de-obra empregada, dos objetivos do trabalho na empresa agrícola - por exemplo, visa à subsistência da família e ainda comercializar o excedente produtivo, e, além disso, da renda agrícola gerada pela atividade.

O conceito de agricultura familiar que será aqui adotado é o utilizado pela FAO/INCRA (2000), através da metodologia deste estudo, será caracterizada a direção dos trabalhos no estabelecimento familiar e estabelecido uma área máxima regional para as unidades de produção familiares - na região Sul do Brasil a área máxima regional das propriedades é de 280,5 ha.

Nesse contexto cabe relacionar a agricultura familiar com o conceito de desenvolvimento. A importância do conceito de desenvolvimento local ou sócioespacial, pelo direcionamento de políticas públicas e do engajamento de organizações sociais oferece uma nova perspectiva para o desenvolvimento rural, haja vista, que este desenvolvimento passa pela caracterização do território segundo sua característica própria, possibilitando aos governos locais desenhar ações especificas 
para a resolução dos problemas da localidade. Assim, "as entidades do governo local podem ser a força motora dos esforços de desenvolvimento" (DENARDI et al., 2000, p. 6).

Para Ortega (2006), apesar da grande importância do movimento de globalização, os fortalecimentos das políticas de desenvolvimento local tornam-se imprescindíveis, pois se busca valorizar as diversidades territoriais - econômicas, sociais e políticas. O desenvolvimento da localidade contribui com o combate a pobreza e a exclusão social promovida pelo modelo modernizador conservador, o que impulsiona a inclusão social e a competitividade local nos mercados mais dinâmicos nacionais e internacionais.

O debate sobre o desenvolvimento rural em Mior (2005) é intimamente ligado ao contexto da agricultura familiar, devido em especial a sua reinserção socioeconômica. No Brasil, no entanto, possui diversos enfoques, porém destaca-se o "enfoque agroindustrial", no qual o agricultor familiar vê possibilidades de sua inserção em novas cadeias produtivas de produtos locais, artesanais e agroecológicos.

A agricultura familiar e o desenvolvimento rural compatibilizam-se, pois se assemelham em seus reflexos nos indicadores de melhoras da qualidade de vida no meio rural. Neste aspecto o desenvolvimento rural é definido pela Contag (1997) ${ }^{8}$ apud Denardi et al. (2000) como,

[...] o crescimento da produção, da renda e dos vetores de sua distribuição, via ocupações produtivas, impostos e investimentos produtivos, que realimentam o processo. Implica em uma melhoria generalizada das condições de vida e trabalho da população que habita o meio rural, com acesso aos bens e serviços sociais que devem ser garantidos aos cidadãos. Abrange ainda a formação e desenvolvimento da infra-estrutura econômica e social, pública e privada, de tal forma que os indicadores sociais de qualidade de vida sofrem contínuas elevações (CONTAG, 1997 apud DENARDI et al., 2000, p. 5).

Dentre as diferentes abordagens entre desenvolvimento rural e o desenvolvimento agrícola, este estaria estreitamente ligado ao chamado agronegócio, agribussiness ou complexo agroindustrial. Ou seja, consiste no desenvolvimento modernizador da agricultura, com vistas ao aumento produtivo e dinamismo, aliados a uma maior rentabilidade dos fatores de produção e custos marginais decrescentes 9 (DENARDI et al., 2000). A seguir apresenta-se a metodologia de pesquisa para em seguida a análise de resultados.

\section{Método de Pesquisa}

O método de pesquisa deste trabalho é descritivo e bibliográfico e de aplicação quantitativa estatística. Para a análise quantitativa, primeiro foram definidos os

\footnotetext{
${ }^{8}$ CONTAG. Programa de formação de dirigentes e técnicos em desenvolvimento municipal baseado na agricultura familiar. Brasília, set 1997.

9 Na Teoria da Firma, os custos variáveis correspondem à parcela dos custos totais que dependem da produção, modificando-se de acordo com a variação desta. Assim, os custos marginais são determinados pela relação entre a variação do custo variável total perante as variações da quantidade produzida. Portanto, os custos marginais decrescentes se referem ao fato de que a cada unidade adicional, o custo marginal de produzi-la diminui proporcionalmente ao custo total (CARVALHO, 1998).
} 
municípios paranaenses a serem estudados por possuírem predominantemente uma produção agrícola de base familiar, e posteriormente essas localidades serão selecionadas para uma análise dos seus indicadores econômicos e sociais (Tabela 1).

Tabela 1 - Códigos, indicadores, ano e fonte dos dados utilizados na matriz de correlação, no Paraná

\begin{tabular}{cllc}
\hline Códigos & \multicolumn{1}{c|}{ Indicadores/ Dados } & Ano & Fonte \\
\hline X1 & IDR & 2007 & Melo e Parré 10 \\
X2 & IDH-M & 2000 & IPARDES \\
X3 & Grau de Urbanização & 2000 & IPARDES \\
X4 & Tx. Cresc. Geométrico da População Total & 2000 & IPARDES \\
X5 & Tx. Cresc. Geométrico da População Rural & 2000 & IPARDES \\
X6 & Índice de Gini & 2000 & IPARDES \\
X7 & Índice de Theil & 2000 & IPARDES \\
X8 & Tx. de Pobreza (\%) & 2000 & IPARDES \\
X9 & Tx. de Analfabetismo 15 anos ou mais (\%) & 2000 & IPARDES \\
X10 & Valor Adicionado Per Capita - (R\$ 1,00) & 2005 & IPARDES \\
X11 & População Censitária Total & 2007 & IPARDES \\
X12 & Densidade Demográfica (hab/km2) & 2006 & IPARDES \\
X13 & Consumo de Energia Elétrica (Mwh) & 2006 & IPARDES \\
X14 & No Consumidores de Energia Elétrica & 2006 & IPARDES \\
X15 & Consumo de Ener. Elétrica (Mwh) Per Capita & 2006 & IPARDES \\
X16 & Pessoal Ocupado na Agricultura Familiar & 2006 & IBGE \\
X17 & No de Estabelecimentos da Agricultura Familiar & 2006 & IBGE \\
X18 & Pessoal Ocupado na Agricultura Patronal & 2006 & IBGE \\
X19 & No de Estabelecimentos da Agricultura Patronal & 2006 & IBGE \\
X20 & PIB a Preços Básicos - Total (R\$1.000,00) & 2006 & IPARDES \\
X21 & PIB Per Capita - (R\$ 1,00) & 2006 & IPARDES \\
X22 & PIB do Agronegócio (\%) & 2006 & IPARDES \\
X23 & No de Contratos de Financiamento Agrícola & 2007 & IPARDES \\
\hline
\end{tabular}

Fonte: IBGE, IPARDES, MELO E PARRÉ (2007).

Após isso, a análise dos indicadores foi comparada à média ponderada dos mesmos no Estado do Paraná. Neste ponto, há uma importante limitação, pois a análise comparativa e o cálculo da média dos indicadores contemplarão municípios com as mesmas características, ou seja, que se destacam pela atividade econômica rural. Distinguindo-se apenas entre eles a sua forma de organização da produção. Novamente, caso o resultado da análise demonstre melhores indicadores nas regiões de organização da produção de forma patronal, a hipótese nula será aceita, mas caso haja uma vantagem na organização da produção de base familiar a hipótese nula será rejeitada e a hipótese alternativa será aceita.

O universo da agricultura familiar no Estado do Paraná pode ser caracterizado pelos dados obtidos no Censo Agropecuário do IBGE. O Censo de 1995/1996 compreende as variáveis relacionadas à produção, despesas, receitas, valores, propriedade, financiamentos, investimentos, área, pessoal ocupado, aos dados da pecuária, lavouras, silviculturas e outras informações ligadas à agropecuária.

10Trabalho publicado em 2007, no entanto, o estudo apresenta dados para um modelo construído para o ano de 2000. 
Na pesquisa realizada pela FAO/INCRA (2000) ${ }^{11}$ através dos dados do Censo Agropecuário, a análise sobre a agricultura familiar requer um esforço especial em relação ao tratamento dos dados primários disponíveis, pois neste Censo não há uma separação na forma como os dados estão disponibilizados, desse modo, o estudo abrange as diversidades de condições dos produtores, seus grupos de atividades econômicas e a área total dos estabelecimentos agropecuários.

No Paraná, as recentes transformações na agropecuária, podem ser verificadas no Censo Agropecuário 2006 - Resultados Preliminares. Pelas primeiras variáveis divulgadas, pode-se analisar o pessoal ocupado nos estabelecimentos agropecuários no universo familiar e os ocupados pela produção patronal. A publicação do Censo Agropecuário 2006 - Resultados Preliminares tem o objetivo de fornecer dados primários estruturais e de abrangência nacional sobre a agropecuária brasileira, e os resultados apurados são divulgados para: Brasil, Grandes Regiões, Unidades da Federação, Mesorregiões e Municípios. A seguir apresenta-se a análise dos resultados da pesquisa para em seguida as considerações finais.

\section{Análise dos Resultados}

A análise estatística descritiva, através da matriz de correlação dos indicadores selecionados, busca compreender por meio de dados uma interpretação adequada da realidade que eles representam. No Estado do Paraná, dos 399 municípios, 316 deles foram selecionados para uma análise estatística no intuito de avaliar quais as variáveis que possuem correlação com o desenvolvimento da agricultura familiar paranaense. Para desenvolver o estudo diversos indicadores foram utilizados, os quais estão sintetizados na Tabela 1. Os municípios foram selecionados segundo o Grau de Urbanização em 2000. Assim, participam do estudo aqueles com valores abaixo da média do Estado12, o que caracteriza serem as localidades com maior grau de ruralização. A seleção de municípios com o indicador Grau de Urbanização acima de média do Estado prejudicaria a amostra e consequentemente os resultados, pois incorreria na seleção de localidades essencialmente urbanas, desviando do escopo de análise do presente estudo.

As variáveis utilizadas na análise compreendem a realidade do campo paranaense, para isso segmentam-se em indicadores sociais como o Índice de Desenvolvimento Humano - Municipal (IDH-M) que reflete a qualidade de vida da população nos municípios, e o Índice de Desenvolvimento Rural (IDR) que explica aos fatores que afetam a qualidade de vida no campo. A variável X3 - Grau de Urbanização foi utilizada para o recorte dos municípios analisados e identifica a população , além disso, X4 eX5 medem o comportamento do crescimento geométrico da população total e da população rural, os indicadores X6 e X7 são associados nas medidas de desigualdade entre os habitantes, bem como, X8 - Taxa de Pobreza explica a percentagem de pessoas com condições precárias de sobrevivência, o indicador X9 - Taxa de Analfabetismo 15 anos ou mais indica em níveis percentuais a falta de escolaridade associada às regiões selecionadas, haja vista, no meio rural haver os piores índices de escolaridade (Tabela 1).

${ }^{11}$ Os dados obtidos através da pesquisa realizada pelo convênio de cooperação técnica entre a FAO/INCRA (2000) estão disponíveis no Banco de Dados da Agricultura Familiar (SADE), no sítio eletrônico do INCRA no endereço <http:// www.incra.gov.br>

${ }^{12} \mathrm{~A}$ média do Grau de Urbanização do Estado do Paraná é de 81,4\% em 2000.

Informe Gepec, Toledo, v. 14, n. 2, p. 39-59, jul./ dez. 2010 
Os indicadores X10, X20, X21 e X22 refletem o nível de atividade econômica da região e especificamente do agronegocio, além dos valores per capita nas variáveis PIB e valor adicionado. Os dados referentes à população existente nas determinadas localidades paranaenses e sua representação em detrimento da área do município estão nas variáveis X11 e X12. Sobre a utilização da energia elétrica e sua abrangência recorre-se aos indicadores X13, X14 e X15. As variáveis X16, X17, X18 e X19 são referentes à agricultura familiar e a agricultura patronal, e compreendem o principal foco de estudo dessa análise. O número de contratos de financiamentos agrícolas é representado pela variável X23 e compreende o acesso ao crédito para financiamento da produção dos estabelecimentos rurais.

Após a aplicação dos 23 indicadores selecionados (Tabela 1) em uma análise estatística através de uma matriz de correlação (Apêndice A), os resultados relevantes referentes à agricultura familiar e patronal, com as demais variáveis, estão sintetizados na Tabela 2.

Tabela 2 - Principais resultados obtidos na matriz de correlação para a agricultura familiar e patronal, no Paraná13

\begin{tabular}{lccccc}
\hline \multicolumn{1}{c|}{ Indicadores } & X1 & X14 & X20 & X23 \\
\hline Pessoal Ocup. na Agricultura Familiar - X16 & $\mathbf{0 , 5 3 9}$ & $\mathbf{0 , 5 8 6}$ & $\mathbf{0 , 5 0 2}$ & $\mathbf{0 , 7 9 4}$ \\
$N^{\circ}$ de Estab. da Agricultura Familiar - X17 & $\mathbf{0 , 5 0 4}$ & $\mathbf{0 , 6 1 4}$ & $\mathbf{0 , 5 1 2}$ & $\mathbf{0 , 7 7 2}$ \\
Pessoal Ocup. na Agricultura Patronal - X18 & 0,024 & 0,156 & 0,139 & 0,069 \\
$N^{\circ}$ de Estab. da Agricultura Patronal - X19 & 0,373 & $\mathbf{0 , 6 0 8}$ & $\mathbf{0 , 5 5 0}$ & $\mathbf{0 , 6 4 5}$ \\
\hline
\end{tabular}

Fonte: O Autor

Nota: Valores sinalizados representam os resultados mais relevantes para as respectivas variáveis

Os resultados da Tabela 2 apresentam coeficientes de correlação altamente positivos entre as variáveis X16 e X17 - pessoal ocupado e estabelecimentos na agricultura familiar e a variável X1 correspondente ao IDR (MELO e PARRÉ, 2007). Estes resultados demonstram que nessas localidades onde a agricultura familiar é predominante seus impactos correlacionam-se com o desenvolvimento rural dos municípios, considerando que a presença desse modo de produção não combate totalmente às desigualdades, mas pode amenizá-las. Desse mesmo modo, as atividades predominantemente provenientes de uma agricultura patronal, voltada para o mercado em grande escala e indutora do desenvolvimento agrícola, não possuem alta correlação com o desenvolvimento rural dos municípios estudados.

A agricultura familiar, através de seus indicadores, resultou em uma forte correlação com o número de consumidores de energia elétrica representado na variável X14. A energia elétrica está associada ao desenvolvimento da localidade, pois o crescimento da utilização da energia relaciona-se ao incremento tecnológico. No meio rural, o número de consumidores de energia elétrica correlacionando-se com a agricultura familiar demonstra o incremento de infra-estrutura associado aos estabelecimentos agrícolas, proporcionado por este modo de produção.

O número de estabelecimentos da agricultura patronal positivamente se relaciona ao número de consumidores de energia elétrica devido ao caráter modernizador intrínseco nessas atividades, assim um maior incremento de tecnologia tende a demandar mais eletricidade.

${ }^{13}$ Resultados obtidos para uma análise de 316 municípios selecionados para o estudo. 
O PIB a preços básicos, representado pela variável X20, apresentou uma forte correlação tanto com a agricultura familiar como com a agricultura patronal, isto é reflexo da composição do PIB do agronegócio no PIB total do Estado do Paraná, o qual em 2006, segundo os dados do IPARDES, o agronegócio correspondeu a 8,25\% do PIB paranaense.

Uma política de financiamento agrícola eficaz pode determinar o sucesso dos empreendimentos rurais, por isso o indicador X23 correlaciona-se positivamente com os segmentos agrícolas familiares e patronais, conforme resultados obtidos na matriz de correlação. Demais resultados obtidos na matriz de correlação apresentamse relevantes, como a correlação negativa entre as variáveis X8 e X3 (Apêndice A), o que demonstra a área urbana com menores índices de pessoas vivendo em condições de pobreza, ademais o meio rural brasileiro sempre possuiu os piores índices de qualidade de vida em relação às zonas urbanas.

O número de consumidores de energia elétrica (X14) correlaciona-se negativamente com o PIB do agronegócio (X22), pois uma expansão deste PIB não significa um aumento do número de consumidores de energia, pelo fato de muitos equipamentos agrícolas necessários para o aumento da produtividade, não são movidos à energia elétrica. Por isso uma forte expansão da produção não ocasiona o aumento do número de consumidores no campo. O acesso a energia elétrica no meio rural para o aumento do número de consumidores não está associado a expansão do PIB do agronegócio, mas sim a incentivos advindos de programas sociais que utilizem a eletricidade como vetor de desenvolvimento social e econômico, investindo para levá-la nos locais onde ela ainda não está presente.

A análise dos resultados obtidos na matriz de correlação permite compreender a correlação entre a agricultura familiar e o desenvolvimento rural, correlacionada a variáveis associadas ao desenvolvimento econômico, como o número de consumidores de energia elétrica e o PIB a preços básicos.

No Paraná existiam 321.380 mil propriedades rurais que correspondem à agricultura familiar, segundo os últimos dados disponíveis para essas variáveis de 1995/ 1996, as quais equivalem a 86,9\% dos estabelecimentos e a $41 \%$ da área total do Estado. A agricultura patronal corresponde a 44.273 mil estabelecimentos rurais, o que representa $12 \%$ das propriedades e 58,2\% da área total paranaense. Esses dados podem ser verificados na Tabela 3, que apresenta o número de estabelecimentos, a área e o valor bruto da produção ${ }^{14}$.

Tabela 3 - Número de estabelecimentos rurais, área e valor bruto da produção, no Paraná 1995/ 1996

\begin{tabular}{lcc|c|c|c|c}
\hline \multirow{2}{*}{ Categorias } & \multicolumn{2}{c|}{ Estabelecimentos } & \multicolumn{2}{c|}{ Área Total } & \multicolumn{2}{c}{ Valor Bruto da Produção } \\
\cline { 2 - 7 } & Número & $\%$ & Número & $\%$ & Número & $\%$ \\
\hline TOTAL & 369.875 & 100 & 15.946 .631 .705 & 100 & 5.573 .890 & 100 \\
\hline Familiar & 321.380 & 86,9 & 6.541 .583 .586 & 41 & 2.683 .996 & 48,2 \\
Patronal & 44.273 & 12 & 9.275 .501 .333 & 58,2 & 2.860 .118 & 51,3 \\
Instituições Religiosas & 369 & 0,1 & 14.388 .812 & 0,1 & 4.739 & 0,1 \\
Entidades Públicas & 3.853 & 1 & 115.157 .974 & 0,7 & 25.036 & 0,4 \\
\hline
\end{tabular}

Fonte: IBGE - Censo Agropecuário 1995/ 1996

Nota: Elaboração FAO/ INCRA (2000)

14Para a FAO/INCRA (2000), o valor bruto da produção (VBP) é o somatório do valor da produção colhida e/ ou obtida de todos os produtos animais e vegetais. 
A agricultura patronal demonstra que apesar de possuir menos estabelecimentos rurais no Estado, tem uma área total maior do que a agricultura familiar, esse fato evidencia a concentração fundiária, pois uma parcela menor dos proprietários administra a maior quantidade de terras. No Brasil, para a FAO/INCRA (2000), os estabelecimentos rurais de agricultores familiares representam 85,2\% do total de propriedades, ocupam 30,5\% da área total e o valor bruto da produção corresponde a 37,9\% da agropecuária brasileira.

Segundo Amorim (2007), os dados da safra 1995/1996, demonstram que os principais produtos da agricultura familiar que contribuem para o valor bruto da produção estão nas atividades de produção animal, pois apresentam maior valor agregado. A pecuária de leite é responsável por 13,3\% do VBP da agricultura familiar, seguido por aves e ovos que correspondem a 10,5\% e a pecuária de corte com 9,5\%. Destaca-se que a maioria dos estabelecimentos familiares cultiva milho e feijão, no entanto, essas culturas participam da VBP da agricultura familiar respectivamente com 8,7\% e 3,8\%. Segundo o Ministério do Desenvolvimento Agrário (MDA), no plano Safra Mais Alimentos Agricultura Familiar 2008/2009, o segmento familiar é responsável por 70\% dos alimentos consumidos no Brasil. Ressalta-se, com isso, a importância estratégica da agricultura familiar na produção de alimentos no Brasil, haja vista, o recente movimento em torno de uma possível crise mundial de alimentos, pelo aumento da demanda global nos últimos anos, a agricultura familiar constitui-se de suma importância para contribuir com a garantia da segurança alimentar no país.

Na agricultura familiar paranaense, segundo os dados do Censo Agropecuário 1995/ 1996, do total de estabelecimentos, 75,44\% estão na condição de proprietários, conforme dados da FAO/ INCRA (2000). No Brasil, o percentual de proprietários dos estabelecimentos familiares é de 74,6\% e na região Sul 80,8\% (FAO/INCRA, 2000, p. 20-21).

A maioria absoluta dos produtores encontra-se na condição de proprietários dos estabelecimentos familiares paranaenses, seguidos pelos ocupantes que estão em 8,77\% das propriedades, além dos parceiros com 8,35\% e os arrendatários com 7,44\%

A partir dos dados apresentados na Tabela 4 percebe-se que de acordo com o pessoal ocupado nas atividades agropecuárias, a agricultura familiar coloca-se como a principal geradora de emprego no meio rural.

Tabela 4 - Pessoal ocupado na agropecuária paranaense - 2006

\begin{tabular}{c|c|c|c}
\hline Categorias & Brasil & Região Sul & Paraná \\
\hline Familiar & 12810591 & 2434734 & 868774 \\
Patronal & 3557042 & 449741 & 228664 \\
\hline
\end{tabular}

Fonte: Censo Agropecuário 2006 - Resultados Preliminares

$\mathrm{Na}$ agricultura familiar encontram-se $79,16 \%$ das pessoas ocupadas em atividades agropecuárias no Paraná, enquanto, na agricultura patronal o percentual é de $20,83 \%$. O contingente de pessoas ocupadas na agricultura familiar no Brasil é de 78,04\% e na Região Sul 84,40\%.

A dimensão das propriedades é de suma importância para garantir a viabilidade econômica dos estabelecimentos rurais. A área máxima das propriedades familiares na região Sul é de 280,5 ha. No entanto, no Paraná das 321.380 mil propriedades familiares, somente 2,5\% tem mais de 100 ha, ainda assim, menor da 
que a área máxima regional delimitada. As propriedades menores que 20 ha somam $70,4 \%$ dos estabelecimentos familiares e maiores que 20 ha são $29,6 \%$ das unidades, desse modo, muitas culturas agrícolas podem ser inviabilizadas devido ao tamanho das propriedades (FAO/ INCRA, 2000).

Na região Sul, segundo a FAO/INCRA (2000), a maioria dos agricultores patronais possui estabelecimentos com áreas superiores 100 ha, no entanto, entre os agricultores familiares esse percentual é de 2,9\%. No Paraná, na agricultura familiar apenas 2,5\% dos estabelecimentos possuem mais de 100 ha, assim a grande parcela das propriedades se concentra entre 5 e 20 ha, na qual, somam 45,6\%, entre 20 e 50 ha, $21,3 \%$ das unidades, entre 50 e 100 ha, 5,8\% dos estabelecimentos, e menores que 5 ha, $24,8 \%$ das unidades familiares de produção.

A partir do dimensionamento do tamanho dos estabelecimentos rurais, a eficiência da agricultura familiar é verificada no valor da renda total por hectare/ ano (ha/ ano) da propriedade. Para Niederle e Schneider (2007), a integralização dos agricultores familiares com o mercado revela as diversas ocupações em que este grupo busca sua reprodução social. Através da pluriatividade há a diversificação da renda por esses agricultores, na medida em que, podem-se obter rendas agrícolas e não-agrícolas. Pelo movimento mercantilizador no campo, o agricultor cada vez mais é dependente dos fatores externos a sua unidade de produção, assim o inserindo no aprofundamento das relações sociais e materiais.

As potencialidades da agricultura familiar e sua distribuição espacial no Estado do Paraná podem ser sintetizadas através de alguns indicadores. Os estudos realizados por IPARDES (2004a), Doretto e Laurenti (2007), Melo e Parré (2007) e Poubel (2005) demonstram o processo de desenvolvimento econômico e social oriundo da agricultura familiar naquelas localidades do Estado onde sua presença é predominante.

Nos trabalhos sobre as características das Mesorregiões paranaenses, a agricultura familiar atua com destaque devido a sua importância no Paraná, assim constata-se pelo IPARDES (2004a, p. 71) "a Mesorregião Sudoeste paranaense tem mantido sua característica de locus da agricultura familiar no Estado, tendo em vista que 92,8\% dos estabelecimentos agrícolas possuíam, em 1995, área inferior a 50 hectares". Os territórios, recentemente, tornaram-se importantes objetos de pesquisa, pelas quais fornecem subsídios para a tomada de decisões pelos governos sobre as políticas públicas indutoras de desenvolvimento rural. No Estado do Paraná, o critério utilizado pelo IBGE na subdivisão do território paranaense em dez mesorregiões, pode ser observado na Figura 1. 
Figura 1 - Mapa do Estado do Paraná subdividido de acordo com o critério das mesorregiões geográficas paranaenses

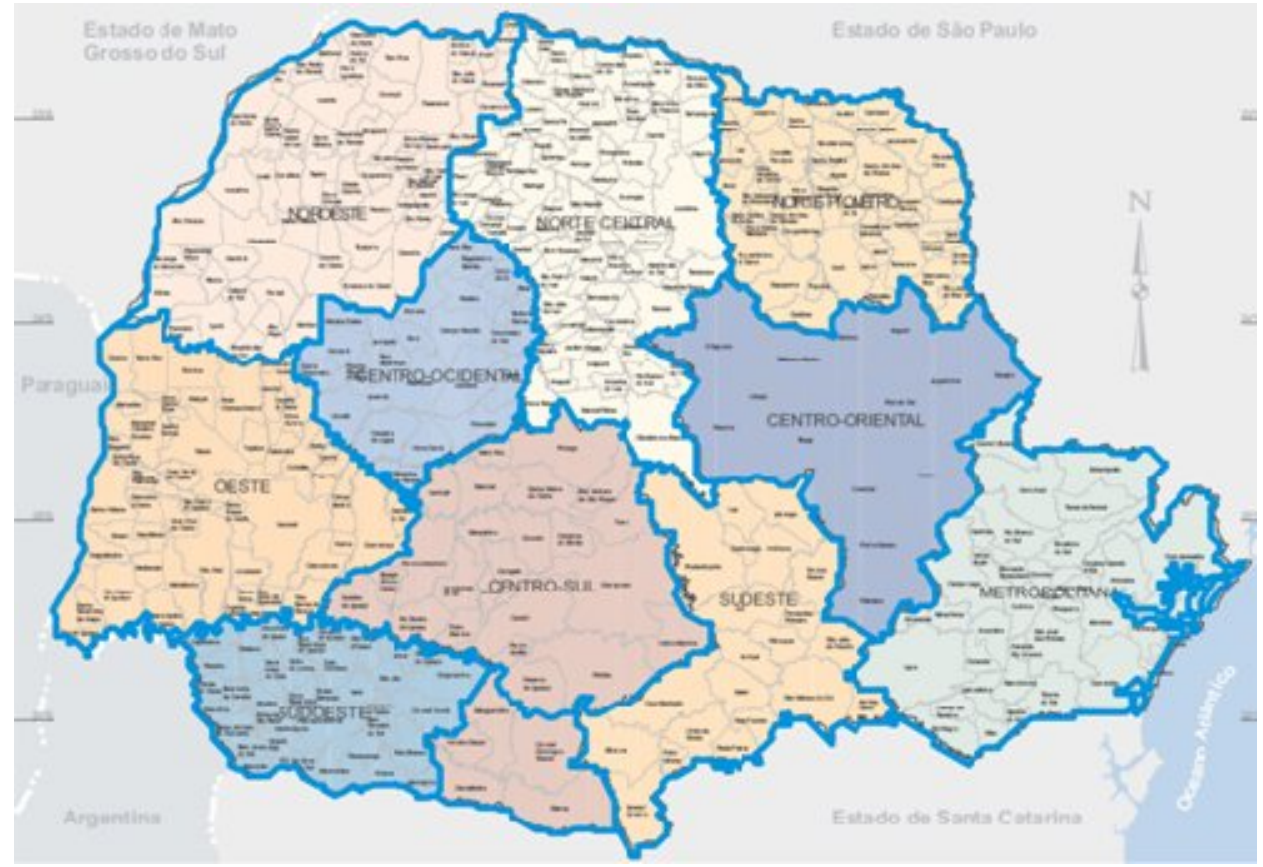

Fonte: Secretaria de Estado do Planejamento e Coordenação Geral (SEPL) ${ }^{15}$

Na metodologia adotada nos estudos de Doretto e Laurenti (2007), na Mesorregião Sudoeste paranaense buscou-se identificar os municípios com maior freqüência na agricultura familiar, de acordo com os dados do Censo Agropecuário de 1995/ 1996, do aparecimento de um sistema de produção predominante (SSP). Para esses autores, segundo a metodologia adotada em seus estudos, a maior freqüência das variáveis de classificação de SSP, dentre os municípios da Mesorregião Sudoeste paranaense, estão concentrados nos municípios de Francisco Beltrão e Capanema.

No município de Francisco Beltrão, o pessoal ocupado na agricultura familiar, em 2006, representa 88,94\%, no município de Capanema, 93,78\% do total das pessoas ocupadas na agropecuária. O percentual de unidades de produção familiar apresentados por essas duas cidades, para dados de 1995/ 1996, encontra-se acima do percentual estadual de 86,9\%, da região Sul de 80,8\% e do Brasil 74,6\%. A predominância da agricultura familiar nessas duas localidades paranaenses corrobora para seus indicadores sociais.

Através do IDH-M dessas localidades, verifica-se que as duas cidades possuem, em 2000, índices superiores à média do Estado de 0,78. Francisco Beltrão apresenta IDH-M de 0,79 e o município de Capanema IDH-M de 0,80. O maior IDHM da Mesorregião Sudoeste paranaense está no município de Pato Branco, o qual concentra 90,7\% dos estabelecimentos agrícolas como familiares, e detém um índice de 0,84. A Mesorregião Sudoeste, reduto da agricultura familiar no Paraná, destacase pelos elevados níveis de indicadores sociais, pois como ressalta o IPARDES (2004a, p. 16) "As Mesorregiões Oeste e Sudoeste paranaense se destacam nessa leitura, por apresentar melhor conjunto de medidas, resultando numa maior proporção de municípios em melhores condições de desenvolvimento humano". Os estudos demonstram que no Estado do Paraná, as tradicionais mesorregiões com

${ }^{15}$ Disponível para consulta no sítio eletrônico < http:// www.sepl.pr.gov.br>. 
uma forte produção pautada pela agricultura familiar, apresentam melhores índices de qualidade de vida em detrimento das localidades com uma produção agrícola essencialmente baseada no modelo patronal.

Os excelentes indicadores de IDH-M da Mesorregião Oeste podem ser explicados pelo alto grau de associativismo e cooperativismo local, para Marschall (2005) o modo de ocupação na Mesorregião foi um fator determinante para o desenvolvimento do cooperativismo, pois na década 1930 os movimentos de expansão da fronteira agrícola incentivaram a ida de migrantes para a região com intuito colonizador. A partir da década de 1960 com o início da modernização agrícola e a inserção de diversos gêneros agrícolas em uma dinâmica de comercialização voltada para o mercado, os antigos colonizadores perceberam a demanda crescente por produtos processados e/ ou industrializados, assim a união desses produtores fez desenvolverem na região um complexo sistema de redes alocadas em diversas estratégias de agroindustrialização.

Nos estudos de Melo e Parré (2007), pelo cálculo do IDR, busca-se estimar e hierarquizar o desenvolvimento rural dos municípios paranaenses em um modelo construído para o ano 2000. Os resultados da análise estatística multivariada, desenvolvida por Melo e Parré (2007), demonstraram as cidades que se destacaram no estudo na Mesorregião Sudoeste, sendo Francisco Beltrão e Dois Vizinhos, ambas com graus de desenvolvimento muito alto. Para o IPARDES (2004a), os municípios de Francisco Beltrão, Pato Branco e Dois Vizinhos formam um eixo integrado nas atividades agroindustriais - principalmente no complexo de aves e suínos. Assim, apesar do movimento de êxodo rural para as cidades, a maioria dos municípios da região permanece rural e com pequenas populações.

$\mathrm{Na}$ mesorregião Sudoeste, tradicional reduto da agricultura familiar paranaense, a média do IDR alcançou o nível de 54,61 e dos 37 municípios da região, 36 obteve índice superior à média Estadual. A mediana do IDR paranaense - número central do conjunto de dados - corresponde a 41,73, assim apenas três regiões possuem médias abaixo desse valor: Noroeste, Norte Pioneiro e Norte Central.

O desenvolvimento rural oriundo da agricultura familiar no campo paranaense reflete-se no indicador do IDR da Mesorregião Sudoeste, em que 97,3\% dos municípios situam-se acima da média do Estado, e assim afirmam o aspecto distributivo que a presença da produção familiar impacta no território. Nesse sentido, segundo Fuentes Llanillo (2007), uma agricultura sustentável é composta por três dimensões: ecológica, econômica e social. A dimensão ecológica é composta pelo desenvolvimento dos agrossistemas - que significa a utilização do território sem a degradação dos seus componentes mantendo suas características fundamentais, pela dimensão econômica que consiste na rentabilidade do sistema - razoável e estável, e a dimensão social, que abrange a distribuição equânime entre a sociedade dos ganhos obtidos pela utilização dos recursos naturais.

A dimensão social advinda do desenvolvimento de uma agricultura sustentável, pelo modelo de produção familiar, pode ser quantificada através do indicador IDH-M. Nos dados contidos na Tabela 5, destaca-se que os municípios com índices elevados de pessoas ocupadas na agricultura familiar, possuem posições de destaque no que se refere ao desenvolvimento humano das respectivas localidades. Nessa tabela, estão selecionados os dez primeiros municípios no ranking do IDH-M no Estado do Paraná - exceto Curitiba por sua característica territorial urbana. Nesses municípios, percebe-se, que a média de pessoal ocupado nos estabelecimentos agropecuários familiares paranaenses é de $82,85 \%$, em 2006, portanto, superior à média do Estado de 79,16\%. 
Tabela 5 - Dez primeiros municípios, excluindo Curitiba, com maior IDH-M do Paraná - 2000

\begin{tabular}{l|c|c|c|c|c}
\hline \multicolumn{1}{c|}{ Município } & Mesorregião & $\begin{array}{c}\text { IDH-M } \\
(2000)\end{array}$ & $\begin{array}{c}\text { Ranking IDH- } \\
\text { M }\end{array}$ & $\begin{array}{c}\text { Agricultura } \\
\text { Familiar } \\
(2006)\end{array}$ & $\begin{array}{c}\text { Agricultura } \\
\text { Patronal } \\
(2006)\end{array}$ \\
\hline Quatro Pontes & Oeste & 0,851 & 2 & $84,69 \%$ & $15,31 \%$ \\
Pato Branco & Sudoeste & 0,849 & 3 & $82,11 \%$ & $17,89 \%$ \\
Entre Rios do Oeste & Oeste & 0,847 & 4 & $76,73 \%$ & $23,27 \%$ \\
Maripá & Oeste & 0,845 & 5 & $93,26 \%$ & $6,74 \%$ \\
Maringá & N. Central & 0,841 & 6 & $74,52 \%$ & $25,48 \%$ \\
Palotina & Oeste & 0,832 & 7 & $82,62 \%$ & $17,38 \%$ \\
Marechal C. Rondon & Oeste & 0,829 & 8 & $89,80 \%$ & $10,20 \%$ \\
Toledo & Oeste & 0,827 & 9 & $83,51 \%$ & $16,49 \%$ \\
Londrina & Noroeste & 0,824 & 10 & $69,48 \%$ & $30,52 \%$ \\
Pato Bragado & Oeste & 0,821 & 11 & $91,74 \%$ & $8,26 \%$ \\
Paraná & Todas & 0,787 & - & $79,16 \%$ & $20,84 \%$ \\
\hline
\end{tabular}

Fonte: PNUD/IPEA/FJ P, IPARDES, IBGE - Censo Agropecuário - 2006

Na Mesorregião Oeste, dos dez municípios selecionados, sete fazem parte de sua geografia, o que demonstra altos índices de qualidade de vida na região. $\mathrm{O}$ pessoal ocupado na agropecuária nos estabelecimentos rurais corresponde a 86,69\% na agricultura familiar e 13,31\% na agricultura patronal (IBGE, 2006).

Por outro lado, apesar dos altos índices que refletem a qualidade de vida nas localidades com predominância da agricultura familiar, o desenvolvimento sustentável no campo, segundo Nazzari, Miyazaki e Bordin (2007), passa pela criação de um ambiente educacional adequado, pois o meio rural brasileiro possui indicadores educacionais péssimos e a falta de qualidade no ensino dissemina a idéia que a migração para as regiões urbanas consiste na busca pela ascensão social.

Após a intervenção estatal no meio rural brasileiro através da criação do PRONAF em 1995, como forma de incentivo ao fortalecimento da agricultura familiar, a sociedade e as diferentes esferas governamentais compreendem que os recursos investidos no desenvolvimento do meio rural pelos programas de incentivos apresentam resultados positivos. Para Marques, Calzavara e Guimarães (2008), o Projeto Paraná 12 meses do Governo do Estado do Paraná em parceria com o Banco Interamericano de Desenvolvimento (BID), demonstrou diversos resultados nos assentamentos e vilas rurais, no combate a pobreza, nos trabalhos de conservação dos recursos naturais e na melhoria da qualidade de vida. O projeto viabiliza o produtor como agente de desenvolvimento de sua própria comunidade através da união entre os membros para o desenvolvimento local.

O Governo do Estado do Paraná compreende as estratégias de sobrevivência do agricultor familiar no mercado, por isso executa o Programa Agroindústria Familiar "Fábrica do Agricultor" que, segundo a Secretaria da Agricultura e do Abastecimento do Paraná (SEAB), possui uma política de ações no sentido de fortalecer as agroindústrias familiares para atuarem na agregação de valor e diferenciação dos produtos. Nesse aspecto, a execução desse programa, consiste pela necessidade de que na agricultura familiar, existam alternativas econômicas que viabilizem esse tipo de modelo de desenvolvimento rural, frente aos sistemas de agricultura empresarial, que operam em grandes escalas de produção, processamento e comercialização. 


\section{Considerações Finais}

A partir da década de 1990 a agricultura familiar passa a ser reconhecida como a mais importante forma de organização da produção para a manutenção de capital social no campo. Os dados estatísticos demonstraram a importância econômica e social das unidades familiares, reconhecendo a agricultura familiar como responsável pelo maior contingente de pessoas ocupadas no meio rural, pela maior eficiência da renda agrícola gerada por suas atividades e por ser responsável pela produção da maioria dos gêneros agrícolas consumidos no país.

No Brasil, os estabelecimentos rurais familiares, segundo dados de 1995/ 1996, correspondem a 85,2\% do total das propriedades, ocupam uma área de 30,5\% da área total e possuem um valor bruto da produção de 37,9\% da agropecuária nacional. No Paraná, as unidades familiares correspondem a 86,9\% do total dos estabelecimentos, ocupam uma área de $41 \%$ e representam 48,2\% do valor bruto da produção.

A análise estatística desenvolvida no presente estudo sobre a agricultura familiar, através de uma matriz de correlação, selecionou os municípios paranaenses caracterizados por um Grau de Urbanização abaixo da média do Estado, ou seja, economias agrícolas, excluindo-se municípios com economias essencialmente urbano-industriais. A estatística identificou que o modo de produção da agricultura familiar correlaciona-se positivamente com os índices associados ao desenvolvimento rural e os indicadores de desenvolvimento econômico.

A distribuição da agricultura familiar no Estado do Paraná é heterogênea, por meio dos estudos do IPARDES (2004a), a Mesorregião Sudoeste destaca-se como o tradicional reduto dos agricultores familiares paranaenses. Para Doretto e Laurenti (2007) os municípios de Francisco Beltrão e Capanema destacam-se como as localidades que possuem um sistema de produção predominante pautado na agricultura familiar. O desenvolvimento desta na Mesorregião, reflete-se no indicador IDR de Melo e Parré (2007), o qual demonstra que dos 37 (trinta e sete) municípios do Sudoeste paranaense, 36 (trinta e seis) deles obtiveram indicadores superiores à média estadual.

A Mesorregião Oeste destaca-se pela presença do associativismo e das cooperativas, as quais são responsáveis pelas estratégias de agroindustrialização dos produtos provenientes da agricultura familiar. Na Mesorregião, o desenvolvimento proveniente das atividades do segmento familiar é identificado pela análise do indicador IDH-M, pois dos 10 (dez) primeiros municípios colocados nesse índice, excluindo-se Curitiba por sua característica urbano-industrial, 7 (sete) deles estão na Mesorregião Oeste paranaense.

A conjuntura atual da agropecuária brasileira, nos dados recentes do IBGE no Censo Agropecuário 2006 - Resultados Preliminares apontam para o aumento do número de estabelecimentos e da área total utilizada nas atividades agropecuárias brasileiras e paranaenses. No entanto, verifica-se, que apesar de um maior número de estabelecimentos agrícolas e uma área maior sendo utilizada para a produção, visivelmente observou-se o movimento de concentração fundiária ocorrido no Estado paranaense na década analisada no estudo.

A agricultura familiar é a responsável pela maior geração de empregos no meio rural, e nos resultados do Censo Agropecuário 2006, o pessoal ocupado nas atividades agropecuárias sofreu uma significativa redução de contingente tanto no Brasil como no Paraná, devido ao incremento técnico-produtivo - a modernização no processo produtivo com a inclusão de máquinas e equipamentos, em comparação ao 
ano de 1996. No entanto, o segmento familiar demonstrou sua capacidade de manutenção das pessoas nas atividades rurais, pois os dados demonstram que a agricultura patronal sofreu uma redução do pessoal ocupado duas vezes maior do que a agricultura familiar.

Nessa conjuntura, verificou-se, a validação da principal hipótese alternativa desse trabalho, através da constatação de que nos lugares onde a agricultura familiar é predominante, obtêm-se melhores indicadores econômicos e sociais. Ademais, o estudo demonstrou como esse modo de produção caracteriza-se por ser o maior gerador de empregos no meio rural e promover a sustentabilidade ambiental na agricultura. Para propostas de novos trabalhos, seria importante analisar a composição da renda obtida na agricultura familiar, a fim de identificar as rendas agrícolas e não-agrícolas desses agricultores, verificando assim se a pluriatividade está inserida na realidade do segmento familiar brasileiro e paranaense.

\section{Referências}

ABRAMOVAY, R. . De volta para o futuro: mudanças recentes na agricultura familiar. In: SEMINÁRIO NACIONAL DO PROGRAMA DE PESQUISA EM AGRICULTURA FAMILIAR DA EMBRAPA. 1. 1997, Petrolina. Anais...Petrolina: EMBRAPA, 1997. p.17-27. Disponível em: $<$ http:// www.econ.fea.usp.br/abramovay/artigos_cientificos/ 1997/ De_volta_para o_futuro.pdf>. Acesso em: 2 out. 2008.

ABRAMOVAY, R. Paradigmas do capitalismo agrário em questão. 2. ed. São Paulo: Hucitec, 1998. 275 p.

AMORIM, L. S. B. Agricultura familiar e redes de desenvolvimento territorial rural: um estudo empírico sobre agroindústria familiar rural no Oeste do Paraná. 2007. Dissertação (Mestrado em Desenvolvimento Regional e Agronegócio) Universidade Estadual do Oeste do Paraná, Toledo, 2007. Disponível em: $\quad<h t t p: / /$ tede.unioeste.br/tede/tde_busca/ arquivo.php?codArquivo=138>. Acesso em: 20 de jul. 2008.

AMORIM, L. S. B., STADUTO, J. A. R. Desenvolvimento territorial rural: estudo empírico sobre agroindústria familiar rural no Oeste do Paraná. In: XLV CONGRESSO DA SOCIEDADE BRASILEIRA DE ECONOMIA, ADMINISTRAÇÃO E SOCIOLOGIA RURAL, Londrina, 2007, 21 p.

BITTENCOURT, G. A., BIANCHINI, V. A agricultura familiar na região sul do Brasil. Consultoria UTF/ 036FAO/INCRA, 1996, 125 p. Disponível em: $<$ http:// gipaf.cnptia.embrapa.br/ publicacoes/ artigos-e-trabalhos/ deser.pdf>. Acesso em: 21 de out. 2008.

CARVALHO, L. C. P. Teoria da firma: a produção e a firma. In: VASCONCELLOS, M. A. S.; PINHO, D. (Org.). Manual de Economia: equipe de professores da USP. 3 ed. São Paulo, 1998, v. 1, p. 144-180.

CHAYANOV, A. V. Sobre a teoria dos sistemas econômicos não capitalistas. In: SILVA, J osé Graziano da; STOLCKE, Verena. A questão agrária. São Paulo: Brasiliense, 1981. p. 137. 
DENARDI et al. Fatores que afetam o desenvolvimento local em pequenos municípios do Estado do Paraná. EMATER, Curitiba, 2000, 50 p. Disponível em: <http:// gipaf.cnptia.embrapa.br/ publicacoes/artigos-e-trabalhos/ fatores-queafetam-o-desenvolvimento-local12.pdf>Acesso em: 20 de ago. 2008.

DORETTO, M.; LAURENTI, A. C. Magnitude e características da agricultura familiar no território Sudoeste do Paraná. In: XLV CONGRESSO DA SOCIEDADE BRASILEIRA DE ECONOMIA, ADMINISTRAÇÃO E SOCIOLOGIA RURAL, Londrina, 2007, $21 \mathrm{p}$.

FAO/INCRA. Novo retrato da agricultura familiar: o Brasil redescoberto. Brasília, 2000. Disponível em: <http:// gipaf.cnptia.embrapa.br/ publicacoes/ artigose-trabalhos/ censo-95-v-final-2000.pdf> . Acesso em 10 de J un. 2008.

FUENTES LLANILLO, R. Indicadores de sustentabilidade da produção familiar mecanizada de grãos em modalidades de plantio direto no norte do Paraná, 2007. 108 f. Tese (Doutorado em Agronomia) - Universidade Estadual de Londrina, Londrina, 2007. Disponível em: <http:// biblioteca.universia.net/ html_bura/ficha/params/id/36481048.html>. Acesso em: 01 de dez. 2008.

GUILHOTO et al. PIB da agricultura familiar: Brasil-Estados. Brasilia: NEAD estudos, $2007 . \quad 171 \quad$ p. $\quad$ Disponível $<$ <ttp:// www.nead.org.br/ index.php?acao=biblioteca\&publicacaoID=350> Acesso em: 18 jun. 2008.

IBGE. Censo Agropecuário: 1995-1996. Rio de J aneiro: IBGE, 1995-1996.

IBGE. Censo Agropecuário: 2006 - Resultados Preliminares. Rio de Janeiro: IBGE, 2006.

IPARDES. Leituras regionais: mesorregiões geográficas paranaenses: sumário executivo, Curitiba, 2004, 32 p. Disponível em: <http:// www.ipardes.gov.br/ modules/ conteudo/ conteudo.php?conteudo=29> . Acesso em: 22 de nov. 2008.

IPARDES. Leituras regionais: mesorregião geográfica Sudoeste paranaense, Curitiba, 2004a, 139 p. <http:// www.ipardes.gov.br/ modules/ conteudo/ conteudo.php?conteudo=29>. Acesso em: 25 de nov. 2008.

KAUTSKY, K. A questão agrária. São Paulo. Nova Cultural, 1986, 401 p.

LÊNIN, V. I. O Desenvolvimento do capitalismo na Rússia: o processo de formação do mercado interno para a grande indústria. São Paulo . Nova Cultural, 1985, $402 \mathrm{p}$.

MARQUES, P.; CALZAVARA, O.; GUIMARÃES, M. O projeto “Paraná 12 meses” em um contexto de desenvolvimento rural sustentável. Acta Scientiarum. Human and Social Sciences, Brasil, 2008. Disponível em: 
<http:// www.periodicos.uem.br/ ojs/ index.php/ ActaSciHumanSocSci/article/ view/ 2 802/ 1907> . Acesso em: 02 de dez. 2008.

MARSCHALL, C. R. Pequena propriedade e cooperativismo no Oeste do Paraná: um estudo a partir da Cooperativa Agroindustrial Lar. 2005. Dissertação (Mestrado em Desenvolvimento Regional e Agronegócio) - Universidade Estadual do Oeste do Paraná,Toledo, $2005 . \quad$ Disponível em: $<$ http:// www.dominiopublico.gov.br/ pesquisa/ DetalheObraForm.do?select_action= \&co_obra=27676> . Acesso em: 28 de nov. 2008.

MELO, O. C., PARRÉ, J. L. Índice de desenvolvimento rural dos municípios paranaenses: determinantes e hierarquização. In; RER, vol. 45, no 02, p. 329-365, Rio de Janeiro, 2007. Disponível em: <http:// www.scielo.br/pdf/resr/v45n2/ 05.pdf>. Acesso em: 10 de set. 2008.

MIOR, L. C. Agricultores familiares, agroindústrias e redes de desenvolvimento rural. Argos: Chapecó, 2005, 338 p.

NAZZARI, K. R.; MIYAZAKI, J.; BORDIN, I. Agricultura familiar e sustentabilidade: os estoques de capital social no Oeste do Paraná. In: II SEMINÁRIO SOBRE SUSTENTABILIDADE EM 2007, 2007, Curitiba,: Unifae, $2007 . \quad$ Disponível em: $<w w w . f a e . e d u /$ publicacoes/pdf/IIseminario/pdf_praticas/praticas_24.pdf $>$. Acesso em 25 de ago. 2008.

NEVES, D. P. Agricultura familiar: quantos ancoradouros! In: BERNARDO M. F.; MARTA I. M. M.; J ULIO C. S. (Org.). Geografia Agrária: teoria e poder. 1 ed. São Paulo: Expressão Popular, 2006, v. 1, p. 211-270.

NIEDERLE, P. A.; SCHNEIDER, S. A pluriatividade na agricultura familiar: estratégia diferencial de distintos estilos de agricultura. In: XLV CONGRESSO DA SOCIEDADE BRASILEIRA DE ECONOMIA, ADMINISTRAÇÃO E SOCIOLOGIA RURAL, Londrina, 2007, 23 p.

ORTEGA, A. C. Atores sociais rurais, governança local e desenvolvimento rural na América Latina. In: XLIV CONGRESSO DA SOCIEDADE BRASILEIRA DE ECONOMIA E SOCIOLOGIA RURAL, Fortaleza, 2006, 20 p.

POUBEL, M. B. P. A territorialidade da ocupação e utilização da terra e os espaços da agricultura familiar. $256 \mathrm{f}$. Tese (Doutorado) - Universidade Federal Rural do Rio de Janeiro, Rio de Janeiro, 2005. Disponível em: $<$ http:// www.dominiopublico.gov.br/ pesquisa/ DetalheObraForm.do?select_action= $\&$ co_obra=101184> . Acesso em 02 de dezembro de 2008.

SCHMITZ, A. P. O que a industrialização tem a dizer sobre as crises do setor agropecuário? In: CASTILHO, L. C., RAMOS, J. M. (Org.). Agronegócio e desenvolvimento sustentável. 1 ed. Francisco Beltrão. Calgan, 2003. p. 9-44.

WANDERLEY, M. N. B. Em busca da modernidade social; uma homenagem a A.V. Chayanov.. . In: FERREIRA, D. D., BRANDENBURG, A (Org.). Para pensar outra agricultura. Curitiba. Editora da UFPR, 1998, v. ,p. 29-49. 
APENDICE A- QUADRO 1A - Matriz de correlação dos municípios selecionados

\begin{tabular}{|c|c|c|c|c|c|c|c|c|c|c|c|c|c|c|c|c|c|c|c|c|c|c|c|}
\hline & $\mathbf{X 1}$ & $\mathrm{X} 2$ & X3 & $\mathbf{X 4}$ & X5 & X6 & $\mathbf{X 7}$ & $\mathbf{X 8}$ & $\mathbf{X 9}$ & X10 & X11 & $\mathrm{X12}$ & X13 & X14 & X15 & X16 & X17 & $\mathbf{X 1 8}$ & $\mathbf{X 1 9}$ & $\mathbf{X 2 0}$ & K21 & $\mathrm{K22}$ & $\mathrm{X23}$ \\
\hline X1 & 1,00 & 0,00 &, 28 & 0,16 & 0,18 &, 40 & 0,41 & 19 & $-0,30$ & 8 & 0,42 & 0 & 26 & 37 & 23 & 54 & 50 & 2 & 37 & 48 & 17 & 1 & 53 \\
\hline $\mathrm{X} 2$ & 0,00 & 1,00 & 0,35 & 0,14 & $-0,02$ & $-0,16$ & $-0,04$ & $-0,78$ & $-0,71$ & 0,38 & 0,15 & 0,21 & 0,20 & 0,25 & $-0,61$ & $-0,02$ & $-0,03$ & 0,01 & 0,04 & 0,28 & ,34 & 0,50 & 0,17 \\
\hline X3 & $-0,28$ & 0,35 & $\mathbf{1 , 0 0}$ & 0,09 & $-0,30$ & $-0,21$ & $-0,18$ & $-0,57$ & $-0,04$ & 0,08 & 0,15 & 0,14 & 0,15 & 0,26 & $-0,22$ & $-0,28$ & $-0,22$ & 0,15 & 0,01 & 0,21 & 0,18 & $-0,47$ & $-0,19$ \\
\hline $\mathbf{X 4}$ & 0,16 & 0,14 & 0,09 & 1,00 & 0,75 & 0,01 & $-0,02$ & $-0,25$ & $-0,40$ & 0,07 & 0,40 & 0,43 & 0,25 & 0,35 & $-0,33$ & 0,11 & 0,07 & 0,00 & 0,11 & 0,37 & 0,06 & $-0,26$ & 0,16 \\
\hline X5 & 0,18 & $-0,02$ & $-0,30$ & 0,75 & 1,00 & 0,05 & 0,00 & 0,0 & $-0,25$ & 0,03 & 0,31 & 0,36 & 15 & 0,22 & $-0,16$ & 0,16 &, 12 & $-0,05$ &, 08 & 0,20 & 0,11 & $-0,03$ & 0,16 \\
\hline X6 & 0,40 & $-0,16$ & $-0,21$ & 0,01 & 0,05 & 1,00 & 0,93 & 0,4 & $-0,01$ & 0,09 & 0,2 & $-0,10$ & 0 & Y & 0,02 & 0,39 & 0,37 & 1 & 0,28 & 0,30 &, 03 & 03 & 0,31 \\
\hline X7 & 0,41 & $-0,04$ & $-0,18$ & $-0,02$ & 0,00 & 0,93 & 1,00 & 0,36 & $-0,10$ & 0,16 & 0,28 & $-0,09$ & 0,24 & 0,26 & $-0,06$ & 0,41 & 0,39 & 0,02 & 0,28 & 0,32 & 0,06 & $-0,01$ & 0,36 \\
\hline $\mathbf{X 8}$ & 0,19 & $-0,78$ & $-0,57$ & $-0,25$ & 0,01 & 0,44 & 0,36 & 1,00 & 0,54 & $-0,27$ & $-0,12$ & $-0,26$ & $-0,18$ & $-0,22$ & 0,53 & 0,23 & 0,20 & $-0,06$ & 0,01 & $-0,23$ & $-0,30$ & 0,50 & 0,04 \\
\hline X9 & $-0,30$ & $-0,71$ & $-0,04$ & $-0,40$ & $-0,25$ & $-0,01$ & $-0,10$ & 0,54 & 1,00 & $-0,31$ & $-0,36$ & $-0,26$ & $-0,29$ & $-0,39$ & 0,64 & $-0,24$ & $-0,20$ & 0,01 & $-0,23$ & $-0,44$ & $-0,30$ & 0,39 & $-0,47$ \\
\hline $\mathbf{X 1 0}$ & 0,18 & 0,38 & 0,08 & 0,07 & $-0,03$ & 0,09 & 0,16 & -0 & $-0,3$ & 1,00 & -0 & $-0,07$ & 0 & 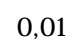 & $-0,55$ & $-0,05$ & $-0,07$ & $-0,01$ & $-0,05$ & 0,26 & 0,60 & 19 & 0,04 \\
\hline X11 & 0,42 & 0,15 & 0 & 0,4 & 0,31 & 0,2 & 0,2 & -0 , & -0 , & -0, & 1,00 & $\mathbf{0}$ & 0 & o & $-0,28$ & 0,63 & 0, & 0,14 & 0 & 0,84 & 0,08 & $-0,47$ & 54 \\
\hline X12 & 0,00 & 0,21 & 0,14 & 0,43 & 0,36 & $-0,10$ & $-0,09$ & $-0,26$ & $-0,26$ & $-0,07$ & 0,54 & 1,00 & 0,17 & 0,46 & $-0,13$ & 0,01 & 0,00 & 0,02 & 0,03 & 0,28 & $-0,07$ & $-0,43$ & 0,04 \\
\hline X13 & 0,26 & 0,20 & 0,15 & 0,25 & 0,15 & 0,21 & 0,24 & $-0,18$ & $-0,29$ & 0,33 & 0,47 & 0,17 & 1,00 & 0,48 & $-0,48$ & 0,22 & 0,22 & 0,06 & 0,25 & 0,62 & 0,35 & $-0,36$ & 0,20 \\
\hline X14 & 0,37 & 0,25 & 0,26 & 0,35 & 0,22 & 0,24 & 0,26 & $-0,22$ & $-0,39$ & 0,01 & 0,97 & 0,46 & 0,48 & 1,00 & $-0,32$ & 0,59 & 0,61 & 0,16 & 0,61 & $\mathbf{0 , 8 7}$ & 0,13 & $-0,55$ & 0,53 \\
\hline X15 & $-0,23$ & $-0,61$ & $-0,22$ & $-0,33$ & $-0,16$ & 0,02 & $-0,06$ & 0,53 & 0,64 & $-0,55$ & $-0,28$ & $-0,13$ & $-0,48$ & $-0,32$ & $\mathbf{1 , 0 0}$ & $-0,09$ & $-0,05$ & 0,00 & $-0,13$ & $-0,46$ & $-0,48$ & 0,41 & $-0,22$ \\
\hline X16 & 0,54 & $-0,02$ & $-0,28$ & 0,11 & 0,16 & 0,39 & 0,41 & 0,23 & $-0,24$ & $-0,05$ & 0,63 & 0,01 & 0,22 & 0,59 & $-0,09$ & 1,00 & 0,98 & 0,08 & 0,68 & 0,50 & $-0,04$ & $-0,11$ & 0,79 \\
\hline $\mathbf{X 1 7}$ & 0,50 & $-0,03$ & $-0,22$ & 0,07 & 0,12 & 0,37 & 0,39 & 0,20 & $-0,20$ & $-0,07$ & 0,64 & 0,00 & $0, \angle 2$ & 0,01 & $-0,05$ & 0,90 & 1,00 & 0,1 & 0,72 & 0,51 & $-0,04$ & $-0,13$ & 0,77 \\
\hline X18 & 0,02 & 0,01 & 0,15 & 0,00 & $-0,05$ & 0,01 & 0,02 & $-0,06$ & 0,01 & $-0,01$ & 0,14 & 0,02 & 0,06 & 0,16 & 0,00 & 0,08 & 0,11 & 1,00 & 0,26 & 0,14 & 0,03 & $-0,02$ & 0,07 \\
\hline X19 & 0,37 & 0,04 & 0,01 & 0,11 & 0,08 & 0,28 & 0,28 & 0,01 & $-0,23$ & $-0,05$ & 0,60 & 0,03 & 0,25 & 0,61 & $-0,13$ & 0,68 & 0,72 & 0,26 & 1,00 & 0,55 & 0,08 & $-0,18$ & 0,65 \\
\hline X20 & 0,48 & 0,28 & 0,21 & 0,37 & 0,20 & 0,30 & 0,32 & $-0,23$ & $-0,44$ & 0,26 & 0,84 & 0,28 & 0,62 & 0,87 & $-0,46$ & 0,50 & 0,51 & 0,14 & 0,55 & 1,00 & 0,48 & $-0,50$ & 0,49 \\
\hline X21 & 0,17 & 0,34 & 0,18 & 0,06 & $-0,11$ & 0,03 & 0,06 & $-0,30$ & $-0,30$ & 0,60 & 0,08 & $-0,07$ & 0,35 & 0,13 & $-0,48$ & $-0,04$ & $-0,04$ & 0,03 & 0,08 & 0,48 & $\mathbf{1 , 0 0}$ & $-0,29$ & 0,08 \\
\hline X22 & $-0,01$ & $-0,50$ & $-0,47$ & $-0,26$ & $-0,03$ & 0,03 & $-0,01$ & 0,50 & 0,39 & $-0,19$ & $-0,47$ & $-0,43$ & $-0,36$ & $-0,55$ & 0,41 & $-0,11$ & $-0,13$ & $-0,02$ & $-0,18$ & $-0,50$ & $-0,29$ & 1,00 & $-0,14$ \\
\hline $\mathbf{X 2 3}$ & 0,53 & 0,17 & $-0,19$ & 0,16 & 0,16 & 0,31 & 0,36 & 0,04 & $-0,47$ & 0,04 & 0,54 & 0,04 & 0,20 & 0,53 & $-0,22$ & 0,79 & 0,77 & 0,07 & 0,65 & 0,49 & 0,08 & $-0,14$ & 1,00 \\
\hline
\end{tabular}

Fonte: Dados da pesquisa

Informe Gepec, Toledo, v. 14, n. 2, p. 39-59, jul./ dez. 2010 